\title{
Direct costs of occupational asthma in Quebec between 1988 and 2002
}

\author{
Jean-Luc Malo MD, Jocelyne L'Archevêque RT, Heberto Ghezzo PhD
}

J-L Malo, J L'Archevêque, H Ghezzo. Direct costs of occupational asthma in Quebec between 1988 and 2002. Can Respir J 2008;15(8):413-416.

BACKGROUND: Forty to 70 cases of occupational asthma due to sensitization to an agent present in the workplace are accepted each year by the Commission de la santé et de la sécurité du travail, the Quebec medicolegal agency.

OBJECTIVES AND METHODS: In a random sample of eight to 10 accepted claims per year from 1988 to 2002, the direct costs of compensation for loss of income (CLI) and compensation for functional impairment (CFI), as well as the associations of these costs with selected variables, were assessed.

RESULTS: Mean costs (presented as Canadian dollars $\times 10^{3}$ ) of CLI, CFI and total were $72.5,11.7$ and 92.8, respectively, while the median costs were 40.7, 7.6 and 61.3 for CLI, CFI and total, respectively. Median CLI costs were significantly higher in men than women (69.9 versus 13.1), workers aged 40 years or older versus those younger than 40 years $(90.1$ versus 27.4 ), workers with occupational asthma due to workplace exposure to low versus high molecular weight agents (51.2 versus 38.6), and workers taking inhaled steroids at diagnosis (92 versus 52 ) and reassessment (81 versus 35 ). Median CFI costs were also higher in those requiring retraining (10.4) and taking early retirement (61.8) than workers who stayed with the same employer but in a different job (5.4). Median CFI costs were significantly higher for individuals being treated with inhaled steroids at the time of diagnosis (14.0 versus 5.2 ) and reassessment (13 versus 6$)$, and for those left with bronchial hyperresponsiveness (9.5 versus 0.8 ) related to forced expiratory volume in $1 \mathrm{~s}$ and forced expiratory volume in $1 \mathrm{~s} /$ forced vital capacity.

CONCLUSION: Age, sex, nature of occupational agent, treatment with inhaled steroids and type of rehabilitation all affect CLI, whereas lung function status at baseline and reassessment is related to CFI.

Key Words: Asthma in the workplace; Costs; Occupational asthma

ccupational asthma (OA) is a type of asthma that is 'caused' by the workplace. Two varieties have been proposed: one due to sensitization to a workplace agent with a latency period necessary for acquiring sensitization, and the other is due to a workplace agent not requiring a latency period, called reactive airways dysfunction syndrome or irritantinduced asthma (1).

Workers with OA are different from workers with pneumoconiosis because they are generally younger and more likely to benefit from satisfactory rehabilitation programs (2). Also, the type of impairment or disability is different from the one for pneumoconiosis because workers with $\mathrm{OA}$ are often left with permanent asthma, a condition with symptoms that are at least partially reversibile with anti-inflammatory and bronchodilator therapy (2).

\section{Les coûts directs de l'asthme professionnel au Québec entre 1988 et 2002}

\begin{abstract}
HISTORIQUE : Chaque année, la Commission de la santé et de la sécurité du travail, l'agence médicolégale du Québec, accepte de 40 à 70 cas d'asthme professionnel causés par une sensibilisation à un agent présent en milieu de travail.
\end{abstract}

OBJECTIFS ET MÉTHODOLOGIE : Dans un échantillon aléatoire de huit à dix réclamations par année entre 1988 et 2002, les auteurs ont évalué les coûts directs du dédommagement pour perte de revenu (DPR) et $\mathrm{du}$ dédommagement pour atteinte fonctionnelle (DAI), ainsi que l'association de ces coûts avec des variables sélectionnées.

RÉSULTATS : Les coûts moyens (présentés en dollars canadiens $\times 10^{3}$ ) du DPR, du DAI et du total s'établissaient à $72,5,11,7$ et 92,8, respectivement, tandis que les coûts médians correspondaient à 40,7, 7,6 et 61,3, respectivement. Les coûts du DPR médian étaient considérablement plus élevés chez les hommes que chez les femmes (69,9 par rapport à 13,1), chez les travailleurs de plus de 40 ans que chez ceux qui étaient plus jeunes (90,1 par rapport à 27,4), chez les travailleurs atteints d'asthme professionnel causé par une exposition professionnelle à des agents de faible poids moléculaire plutôt que de poids moléculaire élevée (51,2 par rapport à $38,6)$ et chez les travailleurs qui prenaient des stéroïdes en aérosol au diagnostic (92 par rapport à 52) et à la réévaluation (81 par rapport à 35). Les coûts de DAI médian étaient également plus élevés chez ceux qui avaient besoin d'une rééducation $(10,4)$ et qui prenaient une retraite anticipée $(61,8)$ que chez ceux qui conservaient le même employeur mais adoptaient un autre travail $(5,4)$. Les coûts de DAI médian étaient considérablement plus élevés chez les personnes traitées à l'aide de stéroïdes en aérosol au moment du diagnostic (14,0 par rapport à 5,2) et de la réévaluation (13 par rapport à 6) et chez ceux qui conservaient une hypersensibilité bronchique $(9,5$ par rapport à 0,8$)$ reliée au volume expiratoire maximal par seconde et au ratio entre le volume expiratoire maximal par seconde et la capacité vitale.

CONCLUSION : Lâge, le sexe, la nature de l'agent professionnel, le traitement avec des stéroïdes en aérosol et le type de réadaptation influent tous sur le DPR, tandis que la fonction pulmonaire de départ et à la réévaluation est liée au DAI.

The cost of OA in terms of compensation for loss of income (CLI) and compensation for functional impairment (CFI) was previously assessed for workers compensated by the Commission de la santé et de la sécurité du travail (CSST) of Quebec, for the years 1986 to 1988 (3). During this period, the mean total cost for each case was found to be approximately $\$ 50,000$. CLI mainly includes compensation for lost salary ( $90 \%$ of salary) during the readaptation period after the worker starts being no longer exposed to the causal agent (up to two years). CFI corresponds to a lump sum allocated at the time the worker is reassessed for disability two years after diagnosis and removal from exposure. This allocation is based on the percentage of disability and age. Total cost primarily consists of CLI and CFI, although asthma medication costs and professional fees are also covered by the CSST from the time of diagnosis for life. After

Axe de recherche en santé respiratoire, Hôpital du Sacré-Coeur de Montréal, Montréal, Québec

Correspondence: Dr Jean-Luc Malo, Department of Chest Medicine, Hôpital du Sacré-Coeur de Montréal, 5400 West Gouin Boulevard, Montreal,

Quebec H4J 1C5. Telephone 514-338-2796, fax 514-338-3123, e-mail maloj@meddir.umontreal.ca 
age 55 years, workers are offered permanent CLI until 65 years of age. With regard to CFI, the CSST medical boards use a scale based on airway calibre and responsiveness, as well as on the severity of asthma as reflected by the need for inhaled steroids (2).

We wanted to re-examine these costs over a more prolonged period, more likely to reflect economic cycles, and relate these costs to anthropometric, clinical and functional variables at the time of diagnosis and reassessment, which is generally carried out two years after diagnosis.

\section{SUBJECTS AND METHODS}

The Quebec CSST was contacted to obtain information for a random selection of 10 subjects per year who received compensation for OA on a yearly basis between 1988 and 2002, inclusively. After examining files, key information related to costs or diagnosis (possible cases of OA without a latency period) was found to be missing in a few instances. Therefore, depending on the year, eight to 10 subjects with $\mathrm{OA}$ were retained. In the other instances, although there might have been missing data, these were not considered crucial. The following information was collected:

- costs for CLI and CFI as well as total cost;

- sex and age;

- CSST regional offices categorized into three regions: the Montreal area, the Québec City area and the rest of Quebec;

- type of agent causing OA, classified as either high or low molecular weight agents;

- inhaled steroids at the time of diagnosis and reassessment;

- functional variables at the time of diagnosis and reassessment: forced expiratory volume in $1 \mathrm{~s}\left(\mathrm{FEV}_{1}\right), \mathrm{FEV}_{1} /$ forced vital capacity (FVC), and provocative concentration of methacholine causing a 20\% fall in $\mathrm{FEV}_{1}$;

- type of CLI in the first two years after diagnosis: return to work for the same employer in a different job, work for a different employer without a training program, work for a different employer with a training program, retired and unemployed; and

- proportion of permanent disability that was allocated at the time of reassessment according to a scale (2).

The protocol was accepted by the CSST and the Ethics Committee at Hôpital du Sacré-Coeur de Montréal (Montreal, Quebec).

\section{Statistical analysis}

Because data were not normally distributed, the Kruskal-Wallis rank sum test was used for all comparisons. Regression analysis was also used to relate costs to functional variables. All analyses were performed with SPSS 14.0 for Windows (Statistical Products and Service Solution, USA) and S-Plus 2000. P<0.05 was considered to be statistically significant.

\section{RESULTS}

A total of 140 claims were kept for analysis in the 15-year period (eight to 10 claims per year). The mean $( \pm$ SD) costs (presented as Canadian dollars $\times 10^{3}$ ) for CLI, CFI and total were $72.5 \pm 78$,
$11.7 \pm 12$ and $92.8 \pm 86$, respectively, while median costs were 40.7, 7.6 and 61.3 for CLI, CFI and total, respectively.

Table 1 presents the associations of these costs with selected anthropometric, administrative, clinical and functional variables. The mean costs for CLI were higher for men than women, and higher for workers aged 40 years or older than those younger than 40 years of age. Costs for the two largest urban areas (Montreal and Quebec City) did not vary versus the rest of Quebec. Costs for CLI and total costs were higher for those who had retired (aged 55 years or older) or were still unemployed at the time of reassessment. CLI and total costs were higher for cases of asthma caused by low molecular weight agents ( $n=73$, including 25 workers with OA due to isocyanates) versus high molecular weight agents $(n=51)$.

All costs were higher for workers with more severe asthma, as reflected by the need for inhaled steroids at the time of diagnosis and reassessment. Although only significantly higher in the case of CFI, costs of CLI and CFI were higher for subjects with abnormal $\mathrm{FEV}_{1}$ values at diagnosis and reassessment. Similar findings were obtained by examining $\mathrm{FEV}_{1} / \mathrm{FVC}$ values (results not shown). CFI costs were also higher for workers with significant bronchial hyperresponsiveness (all workers had significant bronchial hyperresponsiveness at the time of diagnosis). CFI cost was directly related to the proportion of permanent impairment that was allocated $\left(\mathrm{r}^{2}=0.81\right) . \mathrm{FEV}_{1}$ in per cent predicted both at diagnosis $\left(r^{2}=0.35\right)$ and reassessment $\left(r^{2}=0.42\right)$ was significantly related to CFI costs. Significant correlations were also found using the ratio $\mathrm{FEV}_{1} / \mathrm{FVC}$ in per cent predicted $\left(\mathrm{r}^{2}=0.29\right.$ at diagnosis and $r^{2}=0.47$ at reassessment).

Table 2 presents the median values with distribution of quantile values for all indexes that were significant according to Table 1 . For age and sex, differences up to the 25 th percentile are minimal, while they become more apparent at higher percentiles. With regard to the type of readaptation, the costs for working for a different employer, with or without retraining, were distributed in a proportional way along the scale, whereas the costs for those who retired were proportionally higher for the $25 \%$ and $50 \%$ quantiles. For the type of occupational agent, the situation is different; the cost of the most severe cases are equally expensive, while for mildly and moderately severe cases, the cost of OA due to low molecular weight agents is greater than that for high molecular weight agents.

\section{DISCUSSION}

Our study shows a significant increase in direct compensation costs for OA with a latency period, in Quebec. For the period between 1988 and 2002, the mean total cost $\left(\mathrm{CDN} \$ \times 10^{3}\right)$ was $93 \pm 86$, whereas the mean total cost between 1986 and 1988 was 49 (range 2.1 to 330.9) (3). The increase principally affected CLI, and CFI costs declined. Part of the increase in CLI and total costs is related to inflation (approximately $2 \%$ per year in Canada). Our study did not include all cases of OA accepted by the Quebec CSST between 1988 and 2002 - our study is based on a random sample. However, we have no reason to believe that this sample is not representative of the whole population. The advantage of selecting such a sample is that the identification of cases is more precise, which allowed us to relate costs to selected variables. 
TABLE 1

Association of costs with anthropometric, administrative, clinical and functional variables

\begin{tabular}{|c|c|c|c|}
\hline & $\begin{array}{l}\text { Compensation for loss of income, } \\
\qquad \mathrm{CDN} \times \$ 10^{3}\end{array}$ & $\begin{array}{l}\text { Compensation for functional } \\
\text { impairment, } \text { CDN } \$ \times 10^{3}\end{array}$ & Total cost, $\mathrm{CDN} \$ \times 10^{3}$ \\
\hline \multicolumn{4}{|l|}{ Sex } \\
\hline Men $(n=94)$ & $87 \pm 86$ & $12 \pm 12$ & $133 \pm 105$ \\
\hline \multicolumn{4}{|l|}{ Age, years } \\
\hline$<40(n=64)$ & $47 \pm 49$ & $10 \pm 6$ & $89 \pm 78$ \\
\hline$\geq 40(n=66)$ & $97 \pm 94^{\star \star \star}$ & $13 \pm 9$ & $144 \pm 108^{\star \star \star}$ \\
\hline Montreal $(n=70)$ & $72 \pm 92$ & $12 \pm 12$ & $113 \pm 107$ \\
\hline Quebec City $(n=16)$ & $85 \pm 70$ & $11 \pm 8$ & $136 \pm 69$ \\
\hline Other $(n=44)$ & $69 \pm 58$ & $12 \pm 12$ & $119 \pm 92$ \\
\hline \multicolumn{4}{|l|}{ Type of rehabilitation program at assessment } \\
\hline Working for the same employer $(n=23)$ & $43 \pm 86$ & $10 \pm 9$ & $72 \pm 93$ \\
\hline Working for a different employer $(n=27)$ & $35 \pm 27$ & $11 \pm 10$ & $83 \pm 41$ \\
\hline Unemployed $(n=36)$ & $100 \pm 86$ & $16 \pm 13$ & $159 \pm 111$ \\
\hline Not reassessed $(n=13)$ & $48 \pm 50^{\star \star \star}$ & $2 \pm 0.7$ & $73 \pm 66^{\star \star \star}$ \\
\hline \multicolumn{4}{|l|}{ Occupational agent } \\
\hline Low molecular weight $(n=73)$ & $80 \pm 73$ & $11 \pm 11$ & $128 \pm 89$ \\
\hline High molecular weight $(n=51)$ & $53 \pm 63^{*}$ & $12 \pm 11$ & $94 \pm 86^{*}$ \\
\hline \multicolumn{4}{|l|}{ Inhaled steroids at diagnosis } \\
\hline Present $(n=57)$ & $95 \pm 90$ & $14 \pm 14$ & $127 \pm 99$ \\
\hline Absent $(n=48)$ & $54 \pm 61^{* \star}$ & $10 \pm 8^{* *}$ & $78 \pm 65^{\star \star *}$ \\
\hline \multicolumn{4}{|l|}{ Inhaled steroids at reassessment } \\
\hline Present $(n=52)$ & $109 \pm 91$ & $19 \pm 14$ & $118 \pm 97$ \\
\hline Absent $(n=53)$ & $44 \pm 53^{\star \star \star}$ & $8 \pm 6^{* \star *}$ & $64 \pm 57^{\star \star \star}$ \\
\hline$\geq 16(n=26)$ & $68 \pm 82$ & $5 \pm 9^{\star \star \star}$ & $90 \pm 90^{*}$ \\
\hline
\end{tabular}

Values are presented as the mean $\pm S D$. ${ }^{*} P \leq 0.05 ;{ }^{*} P \leq 0.01$; ${ }^{* * *} P \leq 0.001$ by nonparametric statistics (Kruskal-Wallis test). FEV ${ }_{1}$ Forced expiratory volume in $1 \mathrm{~s}$; $P C_{20}$ Provocative concentration of methacholine causing a $20 \%$ fall in FEV 1

Direct costs were higher for older subjects, who were also the ones who took early retirement with compensation for CLI between 55 and 65 years of age. Costs were also higher for men than for women due to CLI that covers salary loss, which is likely to be higher for men. CLI covers the cost of salary loss for a period of one to two years after diagnosis, after which a worker is compensated whenever he or she has to be away from work because of an exacerbation of asthma. Men were significantly older than women at diagnosis (42 versus 36 years of age), which can also explain the higher costs for men. In the present sample, a significant proportion of workers $(27.7 \%)$ were still unemployed at the time of reassessment, which may contribute to higher costs. The proportion of unemployed workers at the time of reassessment in the present study is slightly higher than that in a sample of 40 cases who underwent reassessment two years after diagnosis in a recent study by our group (18\%) (4).

The cost of CLI was not related to the administrative area, suggesting that it is no more difficult to relocate workers with
OA from large urban areas versus those from rural areas. CLI programs were more costly in workers with OA due to exposure to low molecular weight agents. In some instances, it is likely that the agent per se plays a role because it may be more difficult to relocate a worker if the responsible agent is present throughout the workplace. However, it is also possible that workers with $\mathrm{OA}$ due to exposure to isocyanates, which represents approximately one-third of cases of OA due to low molecular weight agents, are more difficult to relocate.

The severity of asthma in terms of the need for inhaled steroids at diagnosis and reassessment influenced costs not only in terms of CFI, as expected, but also with regard to CLI. Workers with more severe asthma might therefore be more difficult to relocate to a different job. As expected, airway calibre and hyperresponsiveness at the time of reassessment influenced CFI costs.

Only the principal direct costs were considered in the current study. Other direct costs include professional fees and the 
TABLE 2

Distribution of costs for compensations for loss of income and functional impairment

\begin{tabular}{|c|c|c|c|c|c|c|}
\hline & \multirow[b]{2}{*}{ Median } & \multicolumn{5}{|c|}{ Quantiles } \\
\hline & & $0 \%$ & $25 \%$ & $50 \%$ & $75 \%$ & $100 \%$ \\
\hline \multicolumn{7}{|c|}{ Compensation for loss of income, CDN\$ $\times 10^{3}$} \\
\hline \multicolumn{7}{|l|}{ Sex } \\
\hline Women & 13.1 & 0.1 & 16.6 & 24.9 & 34.1 & 142.0 \\
\hline Men & 69.9 & 0.1 & 19.8 & 62.0 & 122.1 & 398.0 \\
\hline \multicolumn{7}{|l|}{ Age, years } \\
\hline$<40$ & 27.4 & 0.1 & 16.9 & 30.7 & 66.4 & 238.0 \\
\hline$\geq 40$ & 90.1 & 0.1 & 21.2 & 82.3 & 141.0 & 398.0 \\
\hline \multicolumn{7}{|l|}{ Type of readaptation } \\
\hline $\begin{array}{l}\text { Working for the same } \\
\text { employer }\end{array}$ & 5.4 & 0.1 & 1.0 & 3.8 & 52.4 & 398.0 \\
\hline $\begin{array}{l}\text { Working for a different } \\
\text { employer }\end{array}$ & 19.4 & 0.1 & 19.2 & 26.6 & 46.0 & 108.0 \\
\hline $\begin{array}{l}\text { Working for a different } \\
\text { employer with retraining }\end{array}$ & 10.4 & 0.1 & 18.2 & 21.2 & 31.2 & 112.0 \\
\hline Retired & 61.8 & 7.1 & 97.1 & 122.6 & 174.0 & 300.0 \\
\hline Unemployed & 71.2 & 8.5 & 29.7 & 76.6 & 142.0 & 363.0 \\
\hline \multicolumn{7}{|l|}{ Occupational agent } \\
\hline Low molecular weight & 51.2 & 0.6 & 25.0 & 48.0 & 120.0 & 300.0 \\
\hline High molecular weight & 38.6 & 0.1 & 7.8 & 26.6 & 79.1 & 274.0 \\
\hline \multicolumn{7}{|c|}{ Compensation for functional impairment, CDN $\$ \times 10^{3}$} \\
\hline \multicolumn{7}{|c|}{ Inhaled steroids at the time of diagnosis } \\
\hline Present & 14.0 & 1.4 & 2.6 & 12.6 & 20.7 & 52.9 \\
\hline Absent & 5.2 & 1.3 & 2.3 & 5.6 & 20.7 & 52.4 \\
\hline \multicolumn{7}{|c|}{$\mathrm{FEV}_{1}$ at reassessment, $\%$ predicted } \\
\hline$<80$ & 11.4 & 2.5 & 12.6 & 18.2 & 26.8 & 52.4 \\
\hline$\geq 80$ & 6.9 & 1.5 & 2.3 & 6.8 & 13.7 & 29.2 \\
\hline \multicolumn{7}{|l|}{$\mathrm{PC}_{20}$ at reassessment, $\mathrm{mg} / \mathrm{mL}$} \\
\hline$<16$ & 9.5 & 4.7 & 7.6 & 13.5 & 20.7 & 52.4 \\
\hline$\geq 16$ & 0.8 & 1.6 & 1.8 & 2.2 & 4.4 & 47.7 \\
\hline
\end{tabular}

FEV 1 Forced expiratory volume in $1 \mathrm{~s} ; P C_{20}$ Provocative concentration of methacholine causing a $20 \%$ fall in FEV 1

loss of work at the time of the investigation for possible OA. Workers are also compensated for a period of two to three weeks for any of the following examinations that is deemed necessary: an assessment by the committee of chest physicians appointed by the CSST and the Minister of Labour; medical visits in the case of workers who are monitored by peak expiratory flow rates, spirometry, methacholine responsiveness and

\section{REFERENCES}

1. Bernstein IL, Chan-Yeung M, Malo JL, Bernstein DI. Asthma in the Workplace, 3rd edn. New York: Taylor \& Francis, 2006.

2. Bernstein IL, Keskinen H, Blanc PD, Chan-Yeung M, Malo JL. Medicolegal aspects, compensation aspects, and evaluation of impairment/disability. In: Asthma in the Workplace. Bernstein IL, Chan-Yeung M, Malo JL, Bernstein DI, eds. New York: Taylor \& Francis, 2006:319-51.

3. Dewitte JD, Chan-Yeung M, Malo JL. Medicolegal and compensation aspects of occupational asthma. Eur Respir J 1994;7:969-80. induced sputum for periods at work and away from work; and specific inhalation tests. Drugs necessary to control asthma are also refunded by the CSST for the rest of life. We did not assess the direct costs of the other type of OA, irritant-induced asthma, which represents approximately $10 \%$ to $15 \%$ of cases. Such an analysis would have been more difficult to conduct because many workers with irritant-induced asthma are not considered as having an occupational disease but as having a work accident. This means that these workers are not necessarily assessed by committees of chest physicians but rather by their own physicians. It is, therefore, difficult to trace all of these workers. Finally, we did not examine the indirect costs, such as impaired work productivity and the intangible costs from a reduced quality of life (4). However, in the CFI allocation by the CSST, there is a fixed percentage that is considered for the impact on quality of life without considering the variability of this impact on the worker (4).

We did not examine socioeconomic factors such as education level, income, ethnic origin, etc that are likely to affect CLI and CFI. Another study (5) has shown that these factors influence delays in referral, with a deleterious influence on the severity of asthma at the time of reassessment. As discussed by Vandenplas et al (6), OA and work-exacerbated asthma have a serious socioeconomic impact. In addition, the rate of unemployment in the present study is higher than the rate in the general population according to a recent study carried out in Quebec (4). This difference may have a negative impact on the indirect cost of asthma, including reduced workforce participation, changes in job duties as an adjustment to the asthmatic condition, asthma-related lost work days and impaired work effectiveness while on the job. The impact of these socioeconomic variables on costs also needs to be examined.

ACKNOWLEDGEMENTS: The authors sincerely thank Dr Daniel Boucher and Mélanie Vincent, Esq, of the Commission de la santé et de la sécurité du travail of Quebec for allowing access to relevant data and providing helpful suggestions. They also express their gratitude to Kathe Lieber for copy-editing this manuscript.

SUPPORT: This study was supported by the Centre for Asthma in the Workplace, Canadian Institutes for Health Research, the Canadian and Quebec Lung Associations, and the Institut de recherche Robert-Sauvé en santé et sécurité du travail du Québec.

4. Yacoub MR, Lavoie K, Lacoste G, et al. Assessment of impairment/ disability due to occupational asthma through a multidimensional approach. Eur Respir J 2007;29:889-96.

5. Poonai N, van Diepen S, Bharatha A, Manduch M, Deklaj T, Tarlo SM. Barriers to diagnosis of occupational asthma in Ontario. Can J Public Health 2005;96:230-3.

6. Vandenplas O, Toren K, Blanc PD. Health and socioeconomic impact of work-related asthma. Eur Respir J 2003;22:689-97. 


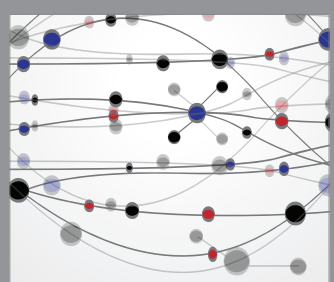

The Scientific World Journal
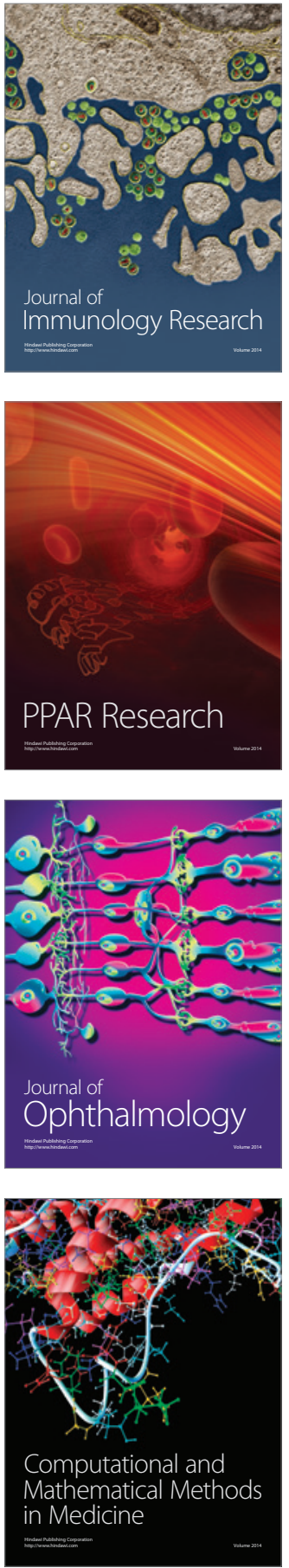

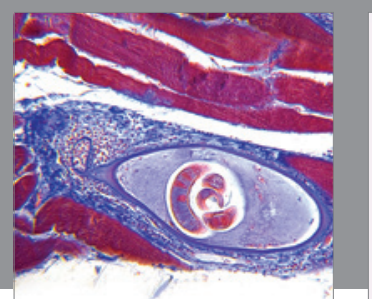

Gastroenterology Research and Practice

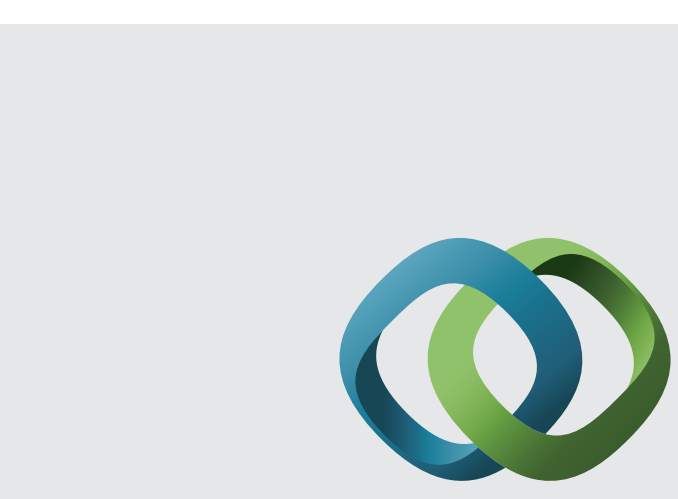

\section{Hindawi}

Submit your manuscripts at

http://www.hindawi.com
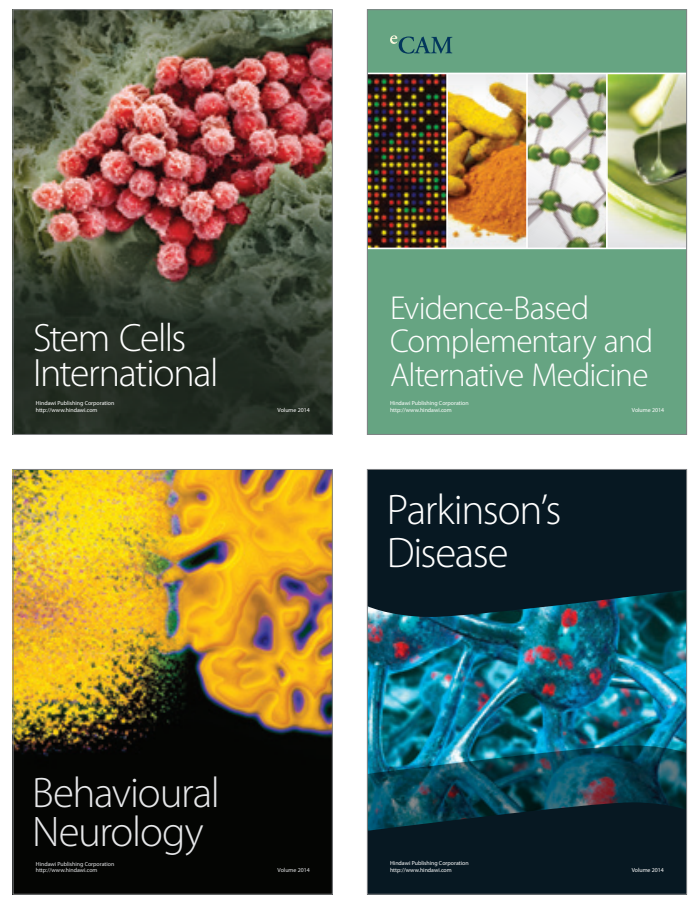
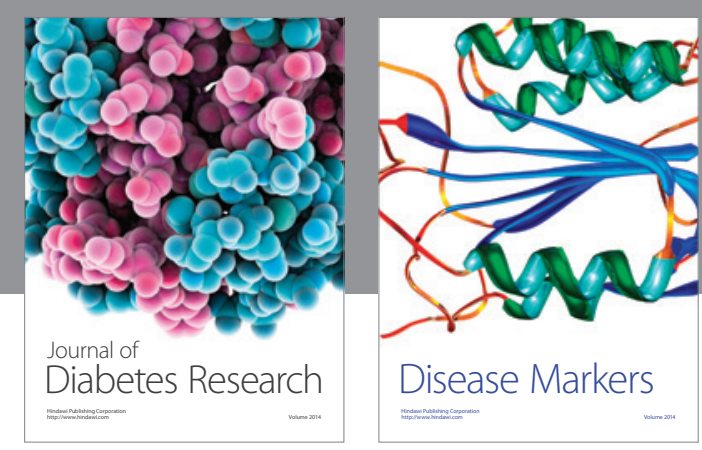

Disease Markers
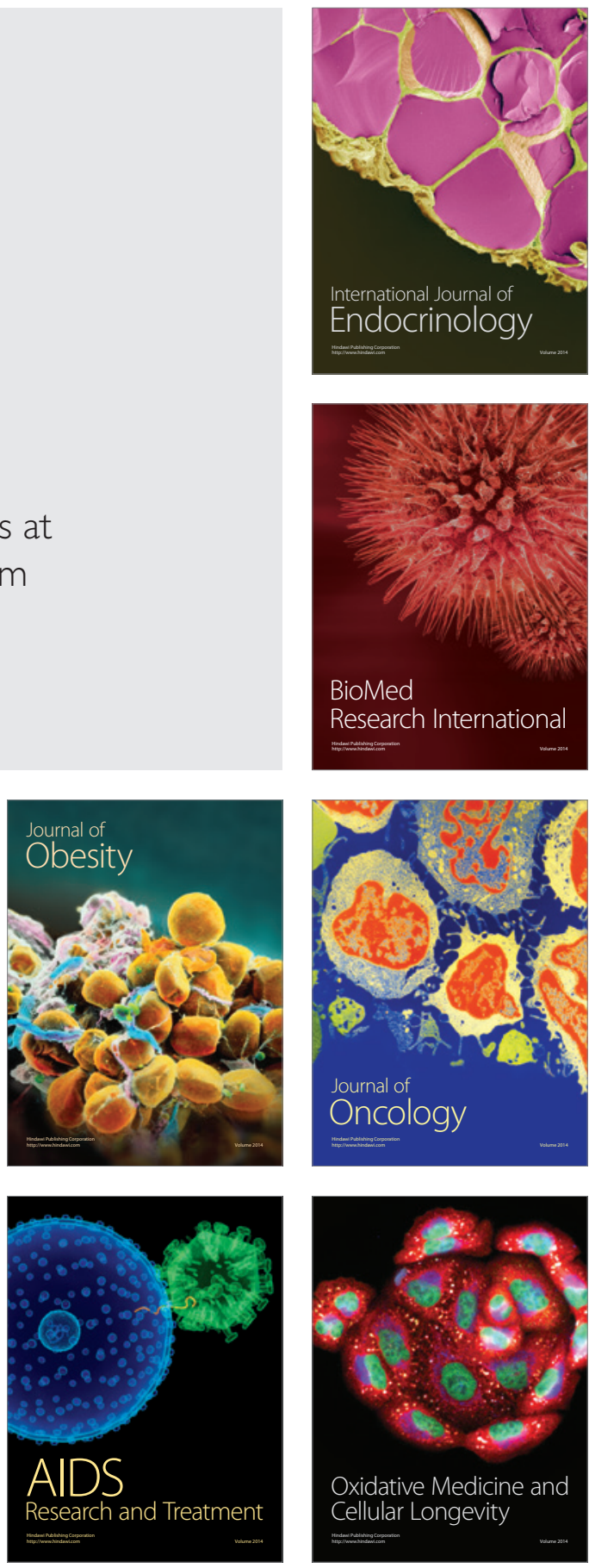